\title{
Flatfoot and Balance Performance Among Junior Secondary School Students in Ibadan, Nigeria
}

\author{
Babatunde O. Adegoke MSCPT, PhD \\ Department of Physiotherapy, College of Medicine, University of Ibadan, Ibadan, Nigeria
}

Chiedozie J. Alumona $B M R(P T), M S C P T$

Department of Physiotherapy, College of Medicine, University of Ibadan, Ibadan, Nigeria

Adetayo A. Adeyemo BSCPT

Department of Physiotherapy, College of Medicine, University of Ibadan, Ibadan, Nigeria.

Adebayo O. Adeyinka MScPT

Department of Physiotherapy, College of Medicine, University of Ibadan, Ibadan, Nigeria

\section{ABSTRACT}

Adequate body balance is important in preventing falls and injuries in children during physically active play and sports at school. The structure of the foot is essential to the ability to balance, but findings from studies comparing balance of children with and without flatfoot have been equivocal. We investigated the prevalence of flatfoot among school children in Ibadan, Nigeria, and compared selected balance indices in participants with and without flatfoot. Participants in this cross-sectional study were 300 junior secondary school students (aged 10-14 years). The navicular drop test, single limb stance test and tandem walk test were used to assess the presence of flatfoot, and static balance and dynamic balance, respectively. Data were summarised using percentages, mean and SD and, analysed with independent t-tests and chi-squared tests. The prevalence of flatfoot was 39.7\%, and while higher in boys $(44.7 \%)$ than girls $(34.9 \%)$, this was not significantly different. Participants with flatfoot had significantly poorer mean static balance measures than those who did not (right: 25.70 [SD 6.55] vs 27.89 [SD 4.92]; left: 26.21 [SD 6.01] vs 28.52 [SD 4.27]), but there was no significant difference in dynamic balance between the groups. When treating children with flatfoot, physiotherapists may consider measuring static balance and, where appropriate, incorporate balance activities as part of the overall management plan.

\section{Adegoke, B. O., Alumona, C. J., Adeyemo, A. A., \& Adeyinka, A. O. (2021). Flatfoot and balance performance among junior secondary school students in Ibadan, Nigeria. New Zealand Journal of Physiotherapy, 49(2), 82-88. https://doi. org/10.15619/NZJP/49.2.04}

Key Words: Adolescence, Balance, Children, Flatfoot, Prevalence

\section{INTRODUCTION}

Balance is a complex motor control task that involves the integration of sensory information about body postures and the execution of appropriate responses of the musculoskeletal system for postural control within the context of the environment and tasks (Karakaya et al., 2015). It is the ability to maintain the body's centre of gravity within the base of support (Yiou, et al., 2017), and its maintenance requires the integration of feedback and movement strategies among the hip, knee, and ankle joints (Panjan \& Sarabon, 2010). The structures of the foot play an important role in standing and walking as they transfer the body's weight to the ground and maintain balance (Hyong and Kang, 2016).

The arches of the foot, namely the medial and lateral longitudinal arches, and the transverse arches, act as shock absorbers and maintain stability during standing and walking (Takata et al., 2013). These arches are maintained by bones, ligaments, joint capsules, and the plantar fascia, and are supported by intrinsic and extrinsic foot muscles; these tissues also provide sensory input (McKeon et al., 2015; Henry et al., 2019). Flatfoot, or pes planus, is a condition characterised by the loss of the medial longitudinal arch of the foot (Lee et al., 2015).

Flatfoot in children is mostly physiological (Lee et al., 2015), as it normally manifests at birth but diminishes in childhood as the arches of the foot develop in the first decade of life (Mosca, 2010). Arch development commences from the age of 3 to 5 years (Lee et al., 2015), progresses between 6 and 7 years (Chang et al., 2014) and is complete before the age of 10 years (Lee et al., 2015; Müller et al., 2012; Tong \& Kong, 2016). However, some children may not have developed arches of the foot, even at maturity (Chang et al., 2014).

Flatfoot is usually accompanied by increased eversion and pronation of the hindfoot (Alam et al., 2019), and increased abduction and supination of the forefoot (Lee \& Kim, 2014). These presentations put the hindfoot and forefoot rotationally in opposite directions, which according to Mosca (2010), gives the impression that the foot has been "wrung out like a towel". These structural deformations lead to decreases in the ability to absorb shock (Kim \& Kim, 2016) and gait efficiency (Lee \& Kim, 2014), and an increase in energy consumption during walking (Tahmasebi et al., 2015). 
Most children with flatfoot rarely experience pain and disability, hence most referrals for clinical evaluation are because of parental concerns (Mosca, 2010). However, some children occasionally present with pain, especially after intense exercise and long walks (Fabry, 2010). Pain may be localised in the foot or be more diffuse (Yeagerman et al., 2011). Another clinical consideration is whether the flatfoot is flexible or rigid. When the flatfoot is flexible, the medial longitudinal arch collapses during weight bearing but reappears in toe standing. In contrast, the arch remains collapsed both during weight- and non-weight bearing in cases of rigid flatfoot (Nemeth, 2011). Jack's test, whereby the great toe is dorsiflexed, thus tightening the plantar fascia, can also be used to distinguish between flexible and rigid flatfoot (Atik \& Ozyurek, 2014). The flatfoot is considered flexible when an arch is formed during the test, and rigid when no arch is formed. Conservative management approaches to flatfoot include walking barefoot, advice and education, footwear selection and modifications, foot orthoses (shoe inserts), and exercise, including stretching and strengthening (Rome et al., 2010).

Children of school age engage in lots of physically active play and sports which require adequate body balance in order to prevent falls and injuries. However, it is not clear if there is a difference in the ability of children with and without flatfoot to balance, given that reports from previous studies have been equivocal. It is believed that flatfoot decreases the proprioceptive and kinesthetic awareness of the foot due to excessive stress that is applied to joint proprioceptors. Thus, Tahmasebi et al. (2015) found that individuals with flatfoot had poorer balance than those without flatfoot when measured with a force plate. Conversely, it is claimed that excessive flattening increases the contact area of the foot, which invariably increases postural balance (Lin et al., 2006). Lin et al. (2006) suggested that individuals with flatfoot have better balance when measured with a force plate because of increased somatosensory feedback to the central nervous system achieved from increased contact area. Given that the arches are fully developed before age 10 (Lee et al., 2015; Müller et al., 2012; Tong \& Kong, 2016), it is important to document the prevalence of flatfoot among children aged 10 years and above. Also, since there is no clear evidence that flatfoot will lead to a painful condition in adulthood (Kwon \& Myerson, 2010), understanding the prevalence in a paediatric population will be useful in reassuring parents that flatfoot could be typical in a large proportion of the population without detriment (Mosca, 2010). Further, data on the prevalence of flatfoot among Nigerian children older than age 10, when the arches are believed to be fully developed, are not available in literature. This study was, therefore, designed to investigate the prevalence of flatfoot among 10- to 14-year-old secondary school students in Ibadan, Nigeria, and to compare the balance performances of those with and without flatfoot.

\section{METHODS}

\section{Participants}

This cross-sectional study involved 300 junior secondary school students (aged 10-14 years). Of the 36 approved public junior secondary schools in the Ibadan North local government area of Oyo State, Nigeria, 10 were selected for the study through systematic sampling. Of the 300 participants, 30 were purposively recruited for the study from each of the selected schools. All pupils met the inclusion criteria of being (a) 10-14 years of age; (b) healthy, with no obvious lower limb deformity, neurological or vestibular dysfunction, or history of fracture to the foot or knee that could impair proprioception and hence balance; and (c) in public junior secondary schools. A nonproportional sampling technique was used to select equal numbers of male and female participants for the study. The minimal sample size of 267 was calculated using the formula of Charan and Biswas (2013):

$$
\begin{aligned}
& \frac{N=\mathrm{Z}_{(1-\alpha / 2)}{ }^{2} p(1-p)}{d^{2}} \\
& \text { Where, } N=\text { sample size } \\
& \mathrm{Z}_{(1-\alpha / 2)}=1.96 \text { (Z-value at } 95 \% \text { confidence interval) } \\
& p=\text { estimated prevalence of pes planus among Nigerian } \\
& \text { school children being } 22.4 \% \text { according to Ezema et al. } \\
& (2014) \\
& d=0.05 \text { (absolute error or precision) }
\end{aligned}
$$

Also, a power analysis was performed a priori using $\mathrm{G} *$ Power 3.1.9.7 software, based on balance data between normal and flatfoot individuals from a study by Tahmasebi et al. (2015). A total of 102 per group was shown to be necessary, based on an effect size of 0.35 , an alpha level of 0.05 , and a power of 0.8 . The minimum calculated sample size was 204 , but 300 participants were recruited for the study. Thus, the study was sufficiently powered.

The study was conducted in accordance with the Declaration of Helsinki and was approved by the University of Ibadan/University College Hospital Research Ethics Committee (approval number $\mathrm{UI} / \mathrm{EC} / 14 / 0276)$. Consent was provided by both the participants' parents and the participants themselves before they took part in the study.

\section{Procedure}

Participants' body weight $(\mathrm{kg})$ and height $(\mathrm{m})$ were measured using a weighing scale and height metre, respectively, and their $\mathrm{BMI}\left(\mathrm{kg} / \mathrm{m}^{2}\right)$ was estimated using the standard formula.

\section{Assessment for flatfoot}

The navicular drop test, as described by Brody (1982) and Hyong and Kang (2016), was used to determine the presence of flatfoot among the participants. This test has been reported to have concurrent validity and reliability (both inter- and intrarater) of 0.6 and 0.9 , respectively, for the assessment of flatfoot (Zuil-Escobar et al., 2018). The participants were instructed to sit comfortably on a chair with arm rests, with their hips and knees flexed at $90^{\circ}$, their ankle joints placed in a neutral position, and their feet touching and resting on the floor. The most protruding part of the navicular tubercle of each foot was identified and marked. The distance between the mark and the ground was then measured with a $1 \mathrm{~mm}$ resolution plastic ruler. The measurement was repeated with the participant in the standing position. Each measurement was taken three times and the mean calculated. The difference between the mean values obtained in sitting and standing was recorded in $\mathrm{mm}$ for both feet. Values from $6 \mathrm{~mm}$ to $9 \mathrm{~mm}$ were considered normal, 
while values equal to or greater than $10 \mathrm{~mm}$ were considered indicative of flatfoot (Hyong \& Kang, 2016).

\section{Static balance assessment}

Participants' static balance was assessed using the single limb stance test. The inter-rater reliability of this test has been reported as 0.9 (Choi et al., 2014; Springer et al., 2007), with a concurrent validity of 0.6 (De Kegel et al., 2010). The test was performed barefooted. Prior to commencing testing, participants were familiarised with the test and allowed to practise the procedure for $5 \mathrm{~min}$ in order to decrease the chance of a learning effect during testing. They were instructed to lift the non-test limb off the ground, flex the hip and knee joints to $90^{\circ}$ while weight-bearing on the test limb, with their arms folded across their chest and both eyes open. Timing began from the point of lifting the leg off the floor and ended when any of the following occurred: (a) displacement of the stance limb, (b) the elevated limb contacting the floor or (c) participants terminating the test. Three trials were performed with the mean used for data analysis as suggested by Springer et al. (2007). A rest period of $30 \mathrm{~s}$ was observed between trials. The time (s) was recorded as a measure of participants' static balance before termination of the test. The test was conducted for both feet.

\section{Dynamic balance assessment}

Dynamic balance was assessed using the tandem walk test as described by and Fregly et al. (1972), and Robertson and Gregory (2017). The tandem walk test has a concurrent validity and reliability (both inter- and intra-rater) of 0.7 and 0.9 , respectively (Koyama et al., 2018). As for static balance assessment, participants were first familiarised with the test and given practice sessions. They were then asked to walk 10 steps barefooted, heel-to-toe without spaces between the steps as fast as possible; these steps were taken along a straight line drawn on the floor. The test was first performed with their eyes open followed by a rest period of $30 \mathrm{~s}$, and then with their eyes closed. The number of correct consecutive steps taken before an error occurred was counted and documented as a measure of participants' dynamic balance. The following constituted errors and, hence, reasons for termination of the test: (a) stepping out of the drawn line, (b) leaving a space between their feet, and (c) opening their eyes during the eyes-closed test. The data for the eyes-closed and eyes-open test conditions were analysed separately.
Data analysis

A post-hoc power analysis performed using $\mathrm{G}$ *Power 3.1.9.7 software on the balance performance of individuals with and without flatfoot revealed that the study was adequately powered (0.88) at alpha of 0.05, with an effect size of 3.7, and a sample size of 119 for flatfoot individuals and 181 for those without flatfoot. Data were analysed using SPSS (version 15). The data were summarised using mean, SD, and percentages. An independent t-test was used to compare height, weight, age, BMI between sexes, and indices of balance performance between those with and without flatfoot. A chi-squared test was used to compare the prevalence of flatfoot in males and females. Inferential statistics were carried out at 0.05 alpha level.

\section{RESULTS}

Participants' demographic data are presented in Table 1. Independent t-tests indicated that the female participants weighed significantly more $(p<0.001)$ and were significantly taller $(p<0.001)$ than their male counterparts, while participants without flatfoot were significantly taller $(p=0.02)$ than those with flatfoot (Table 1). The prevalence of flatfoot among all participants was $39.7 \%$. There was no statistically significant difference between the prevalence of flatfoot in the male (44.7\%) and female (34.7\%) participants (Table 2). The prevalence rates of flatfoot on the right foot, left foot, and both feet were $37.8 \%, 28.6 \%$, and $33.6 \%$, respectively (Table 3 ). Static balance performance was significantly poorer $(p<0.001)$ among participants with flatfoot, but dynamic balance between the groups was not significantly different (Table 4).

\section{DISCUSSION}

The prevalence of flatfoot observed in this study was lower than the rates reported in previous studies. Pfeiffer et al. (2006) reported that the prevalence of flatfoot among 3- to 6-yearold students was 44\%, while Chang et al. (2010) reported $59 \%$ among 7- to 12-year-old children. The higher prevalence reported in the above studies may be attributed to the younger age of the participants. Ezema et al. (2014) and Pourghasem et al. (2016) reported that a decrease in the prevalence of flatfoot is associated with increase in age. It is also plausible that there is an ethnic variation in foot development and morphology that may in turn result in variation in the incidence of flatfoot. Thus, in a study among Spanish children aged 4-13 years, a considerably lower prevalence of $2.7 \%$ was reported (García-

\section{Table 1}

Comparison of Participants' Demographic Characteristics

\begin{tabular}{|c|c|c|c|c|c|c|c|c|c|c|c|c|}
\hline \multirow{3}{*}{ Variable } & \multicolumn{4}{|c|}{ Gender } & \multicolumn{6}{|c|}{ Presence of pes planus } & \multirow{2}{*}{\multicolumn{2}{|c|}{ All }} \\
\hline & \multicolumn{2}{|c|}{ Male } & \multicolumn{2}{|c|}{ Female } & \multicolumn{3}{|c|}{ Yes } & \multicolumn{2}{|c|}{ No } & \multirow[b]{2}{*}{$p$} & & \\
\hline & $M$ & $S D$ & $M$ & $S D$ & $p$ & $M$ & $S D$ & $M$ & $S D$ & & $M$ & $S D$ \\
\hline Age (years) & 13.02 & 1.03 & 12.93 & 1.04 & 0.44 & 12.88 & 1.10 & 13.03 & 0.99 & 0.22 & 12.97 & 1.03 \\
\hline Height (m) & 1.47 & 0.08 & 1.51 & 0.08 & $<0.001 *$ & 1.47 & 0.08 & 1.50 & 0.08 & $0.02 *$ & 1.49 & 0.08 \\
\hline Weight (kg) & 35.15 & 6.36 & 38.44 & 6.95 & $<0.001 *$ & 36.08 & 6.71 & 37.26 & 6.92 & 0.14 & 36.79 & 6.85 \\
\hline BMI $\left(k g / m^{2}\right)$ & 16.15 & 1.56 & 16.85 & 2.11 & $<0.001 *$ & 16.48 & 1.88 & 16.51 & 1.89 & 0.85 & 16.50 & 1.89 \\
\hline
\end{tabular}

*Statistically significant. 
Table 2

Chi-Square Test Comparison of Flatfoot Prevalence in Male and Female Participants

\begin{tabular}{|c|c|c|c|c|c|c|c|}
\hline \multirow[t]{2}{*}{ Prevalence } & \multicolumn{2}{|c|}{$\begin{array}{c}\text { Male } \\
n=150\end{array}$} & \multicolumn{2}{|c|}{$\begin{array}{c}\text { Female } \\
n=150\end{array}$} & \multirow[b]{2}{*}{$p$} & \multicolumn{2}{|c|}{$\begin{array}{c}\text { Total } \\
N=300\end{array}$} \\
\hline & $n$ & $\%$ & $n$ & $\%$ & & $N$ & $\%$ \\
\hline Flatfoot & 67 & 44.7 & 52 & 34.7 & 0.10 & 119 & 39.7 \\
\hline None & 83 & 55.3 & 98 & 65.3 & & 181 & 60.3 \\
\hline
\end{tabular}

Table 3

Flatfoot Prevalence in Male and Female Participants by Foot

\begin{tabular}{|c|c|c|c|c|c|c|}
\hline \multirow[t]{2}{*}{ Foot affected } & \multicolumn{2}{|c|}{$\begin{array}{c}\text { Male } \\
n=67\end{array}$} & \multicolumn{2}{|c|}{$\begin{array}{c}\text { Female } \\
n=52\end{array}$} & \multicolumn{2}{|c|}{$\begin{array}{c}\text { Total } \\
N=119\end{array}$} \\
\hline & $n$ & $\%$ & $n$ & $\%$ & $n$ & $\%$ \\
\hline Right & 24 & 35.8 & 21 & 40.4 & 45 & 37.8 \\
\hline Left & 21 & 31.4 & 13 & 25.0 & 34 & 28.6 \\
\hline Both & 22 & 32.8 & 18 & 34.6 & 40 & 33.6 \\
\hline
\end{tabular}

\section{Table 4}

Comparison of Balance Performance of Participants With and Without Flatfoot Using an Unpaired T-Test

\begin{tabular}{|c|c|c|c|c|c|}
\hline \multirow{3}{*}{ Variable } & \multicolumn{4}{|c|}{ Presence of pes planus } & \multirow[b]{3}{*}{$p$} \\
\hline & \multicolumn{2}{|c|}{ Yes } & \multicolumn{2}{|c|}{ No } & \\
\hline & M & $S D$ & M & $S D$ & \\
\hline \multicolumn{6}{|l|}{ Single limb stance (s) } \\
\hline Right & 25.70 & 6.65 & 27.89 & 4.92 & $<0.001 *$ \\
\hline Left & 26.61 & 6.01 & 28.52 & 4.27 & $<0.001 *$ \\
\hline Eyes open tandem walk test (number of steps) & 6.38 & 3.53 & 6.16 & 3.53 & 0.61 \\
\hline Eyes closed tandem walk test (number of steps) & 1.99 & 2.13 & 1.97 & 1.50 & 0.92 \\
\hline
\end{tabular}

*Statistically significant.

Rodríguez et al., 1999), while $26.6 \%$ was reported among Chinese children aged 6-13 years (Yin et al., 2018).

There is a wide variation in the reported prevalence of flatfoot among children in Nigeria. However, the rates observed from earlier studies, though steadily increasing (Abolarin et al., 2011; Didia et al., 1987; Ezema et al., 2014), have been lower than what was observed in this study. The potential reasons for the variation in the reported rates are differences in methodology and social/environmental factors, such as time spent barefooted. Specifically, parents today are less likely to allow their children to either move around or engage in outdoor games barefooted. This is despite the suggestion that going barefooted is the easiest way to prevent or correct flatfoot in children (McKeon et al., 2015). It is worth noting that three studies (Abolarin et al., 2011; Didia et al.,1987; Ezema et al., 2014) utilised the footprint method as opposed to the navicular drop method used in this study. Interestingly, it has been reported that the footprint method does not always reflect the true medial longitudinal arch of the foot due to its static nature and may, hence, give inaccurate results (Yalçin et al., 2010).

There was no gender difference in flatfoot prevalence, in agreement with findings from a previous similar study (Abolarin et al., 2011). While differences in growth and development in males and females, such as greater hindfoot valgus in males versus a greater hindfoot development in females have been noted (Ezema et al., 2014) these observations appeared to make no difference to the participants in this study.

Participants with flatfoot had significantly poorer static balance than those without, consistent with findings from previous studies (Kim et al., 2015; Tahmasebi et al., 2015). 
To maintain balance, various inputs, such as visual, vestibular, and proprioceptive, are required. Joint, skin and muscles are the main sources of proprioception (Han et al., 2016), and the characteristics of the foot shape can affect the tension of these tissues (Takata et al., 2013). Therefore, any change in foot shape and alignment can affect balance by decreasing the proprioceptive inputs required for balance maintenance. Further, poorer static balance has been attributed to instability of the subtalar joint, as suggested by high values of navicular drop (Kim et al., 2015). The subtalar joint directly controls the stability of the hindfoot and the forefoot (Krähenbühl et al., 2017); hence excessive flexibility of the subtalar joint during weight bearing increases pronation, which might lead to an unstable support base and subsequent decreased instability of the foot (Kim et al., 2015). The single limb stance test is relevant to the children's activities on the playground and at home, in that the position is adopted during activities such as kicking a ball, hopping, skipping, stepping over obstacles, and getting dressed.

There was no significant difference between the dynamic balance of participants with and without flatfoot in this study. This is consistent with findings from previous studies (Hyong \& Kang, 2016; Kim et al., 2015). The lack of difference between the dynamic balance of those with and without flatfoot may be due to reported increased contact points between the foot and the ground, with consequent increased stimulation of the plantar cutaneous receptors (Lin et al., 2006). It can also be attributable to the compensatory postural adjustments during the balance test (Hyong \& Kang, 2016). One of the adjustments may be muscular compensation with the tibialis anterior and posterior, and fibularis longus and brevis muscles (Kim et al., 2015; Mulligan \& Cook 2013). In addition to muscular compensation, other factors may include integration of auditory, somatosensory and biomechanical factors (Kim et al., 2015). The tandem walk test is relevant to children's typical daily activities, such as the balance beam exercise and measuring the width of an improvised goal post during football games.

This study has some limitations. First, it did not gather data on some potentially relevant factors, such as a description of footwear, barefoot versus footwear use, leg dominance, foot-toe muscle strength, habituation, exercise/physical activity level, joint laxity, parental income, or dietary intake. Also, the participants in each group might have exhibited varying degrees of effort during the test procedures, which could have masked or exaggerated the difference between the groups. Therefore, the findings should be interpreted with caution. Future studies should consider the age-by-age prevalence of flatfoot and determine the age at which flatfoot in children will no longer resolve with growth.

\section{Clinical relevance}

Although flatfoot rarely leads to disability in adulthood, it is still a major concern to parents (Kwon et al., 2010). However, the prevalence of flatfoot in this study could be reassuring for parents, as it suggests that asymptomatic flatfoot can be common in a large proportion of the population.

Also, the information on high prevalence of flatfoot among children aged 10-14 years can be useful to physiotherapists, as interventions capable of resolving the condition may be instituted early in childhood in order to reduce its impact. Furthermore, physiotherapists may want to measure balance and, where appropriate, incorporate balance activities as part of the overall management plan.

The navicular drop, single limb stance and tandem walk tests used for the assessment of flatfoot, static balance, and dynamic balance, respectively, are easy to perform and can be done in any setting without the use of high-tech equipment. This information can be useful for clinicians working in any environment.

\section{CONCLUSION}

The prevalence of flatfoot among junior secondary school students in Ibadan, Nigeria, was $39.7 \%$. The students with flatfoot had significantly poorer static balance than those without flatfoot, but the dynamic balance of the groups was not significantly different. Spending quality time barefooted is the easiest way to prevent or correct flatfoot in children, but reassuring parents, appropriate shoe selection, shoe inserts, and exercises are alternative conservative management approaches.

\section{KEY POINTS}

1. The prevalence of flatfoot in 10- to 14-year-old Ibadan students was $39.7 \%$.

2. Static balance was poorer in participants with flatfoot than those without.

3. Dynamic balance was similar between groups.

4. Flatfoot is often benign but can be managed conservatively through spending more time barefooted, advice/education, shoe selection, shoe inserts, and exercises.

\section{DISCLOSURES}

No external funding was received for this study. There are no conflicts of interest which may be perceived to interfere with or bias this study.

\section{PERMISSIONS}

The study was conducted in accordance with the Declaration of Helsinki and its protocol approved by the University of Ibadan/ University College Hospital Research Ethics Committee (approval number UI/EC/14/0276). Consent was provided by both the participants' parents and the participants themselves before they were recruited for the study.

\section{ACKNOWLEDGEMENTS}

The authors would like to thank the principals, teachers and students at the schools where this study was conducted for approving and/or participating in this study.

\section{ADDRESS FOR CORRESPONDENCE}

Chiedozie J Alumona, Department of Physiotherapy, College of Medicine, University of Ibadan, Ibadan, Nigeria.

Email: chiedoziejames@yahoo.com 


\section{REFERENCES}

Abolarin, T., Aiyegbusi, A., Tella, A., \& Akinbo, S. (2011). Predictive factors for flatfoot: The role of age and footwear in children in urban and rural communities in South West Nigeria. The Foot, 21(4), 188-192. https://doi. org/10.1016/j.foot.2011.07.002

Alam, F., Raza, S., Moiz, J.A., Bhati, P., Anwer, S., \& Alghadir, A. (2019). Effects of selective strengthening of tibialis posterior and stretching of iliopsoas on navicular drop, dynamic balance, and lower limb muscle activity in pronated feet: A randomized clinical trial. The Physician and Sports Medicine, 47(3), 301-311. https://doi.org/10.1080/00913847.201 8.1553466

Atik, A., \& Ozyurek, S. (2014). Flexible flatfoot. Northern Clinics of Instanbul, 1(1), 57-64. https://doi.org/10.14744/nci.2014.29292

Brody, D. M. (1982). Techniques in the evaluation and treatment of the injured runner. Orthopaedic Clinincs of North America, 13(13), 541-558.

Chang, C.-H., Chen, Y.-C., Yang, W.-T., Ho, P.-C., Hwang, A.-W., Chen, C.H., Cheng, C.-H., Chang, J.-H., \& Chang, L.-W. (2014). Flatfoot diagnosis by a unique bimodal distribution of footprint index in children. PLOS ONE 9(12), e115808. https://doi.org/10.1371/journal.pone.0115808

Chang, J.-H., Wang, S.-H., Kuo, C.-L., Shen, H. C., Hong, Y.-W., \& Lin, L.-C. (2010). Prevalence of flexible flatfoot in Taiwanese school-aged children in relation to obesity, gender, and age. European Journal of Pediatrics, 169(4), 447-452. https://doi.org/10.1007/s00431-009-1050-9

Charan, J., \& Biswas, T. (2013). How to calculate sample size for different study designs in medical research? Indian Journal of Psychological Medicine, 35(2), 121-125.

Choi, Y. M., Dobson, F., Martin, J., Bennell, K. L., \& Hinman, R. S. (2014). Interrater and intrarater reliability of common clinical standing balance tests for people with hip osteoarthritis. Physical Therapy, 94(5), 696-704 https://doi.org/10.2522/ptj.20130266

De Kegel, A., Dhooge, I., Peersman, W., Rijckaert, J., Baetens, T., Cambier, D., \& Van Waelvelde, H. (2010). Construct validity of the assessment of balance in children who are developing typically and in children with hearing impairments. Physical Therapy, 90(12), 1783-1794. https://doi. org/10.2522/ptj.20100080

Didia, B. C., Omu, E. T., \& Obuoforibo, A. A. (1987). The use of footprint contact index II for classification of flat feet in a Nigerian population. Foot Ankle, 7(5), 285-289. https://doi.org/10.1177/107110078700700504

Ezema, C. I., Abaraogu, U. O., \& Okafor, G. O. (2014). Flat foot and associated factors among primary school children: A cross-sectional study. Hong Kong Physiotherapy Journal, 32(1), 13-20. https://doi.org/10.1016/j. hkpj.2013.05.001

Fabry, G. (2010). Clinical practice. Static, axial, and rotational deformities of the lower extremities in children. European Journal of Pediatrics, 169(5), 529-534. https://doi.org/10.1007/s00431-009-1122-x

Fregly, A. R., Graybiel, A., \& Smith, M. J. (1972). Walk on floor eyes closed (WOFEC): A new addition to an ataxia test battery. Aerospace Medicine, 43(4), 395-399.

García-Rodríguez, A., Martín-Jiménez, F., Carnero-Varo, M., Gómez-Gracia E., Gómez-Aracena, J., \& Fernández-Crehuet, J. (1999). Flexible flat feet in children: A real problem? Pediatrics, 103(6), e84. https://doi.org/10.1542/ peds.103.6.e84

Han, J., Waddington, G., Adams, R., Anson, J., \& Liu, Y. (2016). Assessing proprioception: A critical review of methods. Journal of Sport and Health Sciences, 5(1), 80-90. https://doi.org/10.1016/j.jshs.2014.10.004

Henry, J.K., Shakked, R., \& Ellis, S. J. (2019). Adult-acquired flatfoot deformity. Foot and Ankle Orthopaedics, 4(1), 1-17. https://doi. org/10.1177/2473011418820847

Hyong, I. H., \& Kang, J. H. (2016). Comparison of dynamic balance ability in healthy university students according to foot shape. Journal of Physical Therapy Science, 28(2), 661-664. https://doi.org/10.1589/jpts.28.661
Karakaya, M. G., Rutbil, H., Akpinar, E., Yildirim, A., \& Karakaya, I. Ç. (2015). Effect of ankle proprioceptive training on static body balance. Journal of Physical Therapy Science, 27(10), 3299-3302. https://doi.org/10.1589/ jpts.27.3299

Kim, E.-K., \& Kim, J. S. (2016). The effects of short foot exercises and arch support insoles on improvement in the medial longitudinal arch and dynamic balance of flexible flatfoot patients. Journal of Physical Therapy Science, 28(11), 3136-3139. https://doi.org/10.1589/jpts.28.3136

Kim, J.-A., Lim, O-B., \& Yi, C.-H. (2015). Difference in static and dynamic stability between flexible flatfeet and neutral feet. Gait and Posture, 41(2), 546-550. https://doi.org/10.1016/j.gaitpost.2014.12.012

Koyama, S., Tanabe, S., Itoh, N., Saitoh, E., Takeda, K., Hirano, S., Ohtsuka, K., Mukaino, M., Yanohara, R., Hiroaki, S., \& Kanada, Y. (2018). Intra- and inter-rater reliability and validity of the tandem gait test for the assessment of dynamic gait balance. European of Journal of Physiotherapy, 20(3), 135-140. https://doi.org/10.1080/21679169.2017.1414304

Krähenbühl, N., Horn-Lang, T., Hintermann, B., \& Knupp, M. (2017). The subtalar joint: A complex mechanism. EFORT Open Reviews, 2(7), 309316. https://doi.org/10.1302/2058-5241.2.160050

Kwon, J. Y., \& Myerson, M. S. (2010). Management of the flexible flat foot in the child: A focus on the use of osteotomies for correction. Foot and Ankle Clinics, 15(2), 309-222. https://doi.org/10.1016/j.fcl.2010.02.001

Lee, C.-R., \& Kim, M.-K. (2014). The effects on muscle activation of flatfoot during gait according to the velocity on an ascending slope. Journal of Physical Therapy Science, 26(5), 675-677. https://doi.org/10.1589/ jpts.26.675

Lee, H.-J., Lim, K.-B., Yoo, J., Yoon, S.-W., Yun, H.-J., \& Jeong, T.-H. (2015). Effect of custom-moulded foot orthoses on foot pain and balance in children with symptomatic flexible flat feet. Annals of Medical Rehabilitation, 39(6), 905-913. https://doi.org/10.5535/ arm.2015.39.6.905

Lin, C.-H., Lee, H.-Y., Chen, J.-J. J., Lee, H.-M., \& Kuo, M.-D. (2006). Development of a quantitative assessment system for correlation analysis of footprint parameters to postural control in children. Physiological Measurement, 27(2), 119-130. https://doi.org/10.1088/0967$3334 / 27 / 2 / 003$

McKeon, P. O., Hertel, J. Bramble, D., \& Davis, I. (2015). The foot core system: A new paradigm for understanding intrinsic foot muscle function. British Journal of Sports Medicine, 49(5), 290. https://doi.org/10.1136/ bjsports-2013-092690

Mosca, V.S. (2010). Flexible flatfoot in children and adolescents. Journal of Children's Orthopaedics, 4(2), 107-121. https://doi.org/10.1007/s11832010-0239-9

Müller, S., Carlsohn, A., Müller, J., Baur, H., \& Mayer, F. (2012). Static and dynamic foot characteristics in children aged $1-13$ years. A cross-sectional study. Gait and Posture, 35(3), 389-394. https://doi.org/10.1016/j. gaitpost.2011.10.357

Mulligan, E. P., \& Cook, P. G. (2013). Effect of plantar intrinsic muscle training on medial longitudinal arch morphology and dynamic function. Manual Therapy, 18(5), 425-430. https://doi.org/10.1016/j.math.2013.02.007

Nemeth, B. (2011). The diagnosis and management of common childhood orthopedic disorders. Current Problems in Pediatric and Adolescent Health Care, 41(1), 2-28. https://doi.org/10.1016/j.cppeds.2010.10.004

Panjan, A., \& Sarabon, N. (2010). Review of methods for the evaluation of human body balance. Sport Science Review, 19(5-6), 131-163. https://doi. org/10.2478/v10237-011-0036-5

Pfeiffer, M., Kotz, R., Ledl, T., Hauser, G., \& Sluga, M. (2006). Prevalence of flat foot in preschool-aged children. Pediatrics, 118(2), 634-639. https:// doi.org/10.1542/peds.2005-2126 
Pourghasem, M., Kamali, N., Farsi, M., \& Soltanpour, N. (2016). Prevalence of flatfoot among school students and its relationship with BMI. Acta Orthopaedica et Traumatologica Turcica, 50(5), 554-557. https://doi. org/10.1016/j.aott.2016.03.002

Robertson, M., \& Gregory, R. (2017). Concurrent validation of the tandem walk test as a measure of dynamic walking balance in a healthy population. Physical Therapy and Rehabilitation, 4, 12. https://doi. org/10.7243/2055-2386-4-12

Rome, K., Ashford, R. L., \& Evans, A. (2010). Non-surgical interventions for paediatric pes planus. Cochrane Database of Systematic Reviews. https:// doi.org/10.1002/14651858.CD006311.pub2

Springer, B. A., Marin, R., Cyhan, T. R., Roberts, H., \& Gill, N. W. (2007) Normative values for the unipedal stance test with eyes open and closed. Journal of Geriatric Physical Therapy, 30(1), 8-15. https://doi. org/10.1519/00139143-200704000-00003

Tahmasebi, R., Karimi, M. T., Satvati, B., \& Fatoye, F. (2015). Evaluation of standing stability in individuals with flatfeet. Foot and Ankle Specialist, 8(3), 168-174. https://doi.org/10.1177/1938640014557075

Takata, Y., Matsuoka, S., Okumura, N., Iwamoto, K., Takahashi, M., \& Uchiyama, E. (2013). Standing balance on the ground - the influence of flatfeet and insoles. Journal of Physical Therapy Science, 25(12), 1519 1521. https://doi.org/10.1589/jpts.25.1519

Tong, J. W. K., \& Kong, P. W. (2016). Medial longitudinal arch development of children aged 7 to 9 years: Longitudinal investigation. Physical Therapy, 96(8), 1216-1224. https://doi.org/10.2522/ptj.20150192
Yeagerman, S. E., Cross, M. B., Positano, R., \& Doyle, S. M. (2011). Evaluation and treatment of symptomatic pes planus. Current Opinion in Pediatrics, 23(1), 60-67. https://doi.org/10.1097/MOP.0b013e32834230b2

Yalçin, N., Esen, E., Kanatli, U., \& Yetkin, H. (2010). Evaluation of the medial longitudinal arch: A comparison between the dynamic plantar pressure measurement system and radiographic analysis. Acta Orthopaedica et Traumatologica Turcica, 44(3), 241-245. https://doi.org/10.3944/ AOTT.2010.2233

Yin, J., Zhao, H., Zhuang, G., Liang, X., Hu, X., Zhu Y., Zhang, R., Fan, X., \& Cao, Y. (2018). Flexible flatfoot of 6-13-year-old children: A cross-sectional study. Journal of Orthopaedic Science, 23(3), 552-556. https://doi. org/10.1016/j.jos.2018.02.004

Yiou, E., Caderby, T., Delafontaine, A., Fourcade, P., \& Honeine, J.-H. (2017) Balance control during gait initiation: State-of-the-art and research perspectives. World Journal of Orthopedics, 8(11), 815-828. https://doi. org/10.5312/wjo.v8.i11.815

Zuil-Escobar, J.C., Martínez-Cepa, C.B., Martín-Urrialde, J.A., \& GómezConesa, A. (2018). Medial longitudinal arch: Accuracy, reliability and correlation between navicular drop test and footprint parameters. Journal of Manipulative and Physiological Therapeutics, 41(8), 672-679. https:// doi.org/10.1016/j.jmpt.2018.04.001 